\title{
More Than "Push" and "Pull"? Plant-Soil Feedbacks of Maize Companion Cropping Increase Chemical Plant Defenses Against Herbivores
}

\begin{abstract}
Daniel M. Mutyambai ${ }^{1,2}$, Ethan Bass ${ }^{1}$, Tim Luttermoser ${ }^{3}$, Katja Poveda ${ }^{3}$, Charles A. O. Midega ${ }^{4}$, Zeyaur R. Khan ${ }^{4}$ and André Kessler ${ }^{1 *}$
\end{abstract}

${ }^{1}$ Department of Ecology and Evolutionary Biology, Cornell University, Ithaca, NY, United States, ${ }^{2}$ Department of Biology, South Eastern Kenya University, Kitui, Kenya, ${ }^{3}$ Department of Entomology, Cornell University, Ithaca, NY, United States,

${ }^{4}$ International Centre of Insect Physiology and Ecology, Mbita, Kenya

Plants can alter nutritional availability, structure, and chemistry of the soil they grow in. These soil changes can positively or negatively influence the growth and metabolism of other plants that co-occur or grow later in the conditioned soil. Plant-soil feedbacks could affect community interactions and dynamics but also be applied in sustainable agriculture to promote plant growth and resistance to pests. In this study, we use a maize companion cropping system, commonly known as "push-pull," as a model to investigate soil-mediated effects of functional biodiversity, on maize plant growth, and resistance against insect herbivores. We grew maize in soils collected from push-pull (polyculture) and non-push-pull (monoculture) fields. We evaluated maize performance by measuring plant growth, as well as resistance traits (herbivore oviposition and larval feeding, production of defense-related volatile, and non-volatile secondary defense metabolites). Maize plants grown in soil conditioned by push-pull companion cropping had a higher growth rate compared to those grown in soil from non-push-pull monoculture fields. In addition, soil from push-pull fields induced a constitutively higher and qualitatively different emission of volatile organic compounds than soil from non-push-pull fields. Moreover, secondary defense metabolites such as 2,4-dihydroxy-7-methoxy-2H-1,4-benzoxazin-3(4H)-one (DIMBOA), were produced in larger quantities in plants grown in soil from push-pull fields compared to those from monoculture fields. These soil-mediated alterations in plant secondary metabolism were associated with reduced herbivory by larvae of the stemboring pest Chilo partelllus. This study provides novel evidence that plant-soil feedbacks can affect plant metabolism, growth, and resistance to pests. The observed soil-mediated effects on maize plant secondary metabolism can be viewed as emergent properties of plant community composition as well as a potent mechanism of associational resistance. In addition, these soil-conditioning effects provide a novel pest control mechanism of push-pull companion cropping.

Keywords: plant defenses, plant-soil feedback, push-pull technology, sustainable agriculture, local biodiversity, associational resistance, functional diversity 


\section{INTRODUCTION}

In terrestrial ecosystems, plants not only extract nutrients from the soil, but also affect the soil physical and chemical conditions through processes such as depletion of nutrients, incorporation of atmospheric elements, secretion of root exudates, and contextdependent accumulation of organic matter (Bever et al., 1997; Wardle et al., 2004; Harrison and Bardgett, 2010). Plant effects on the soil may differ greatly between plant species as plants vary in quality and quantity of biomass and the chemical composition of root exudates or the ability to incorporate free elements into the soil (Wardle et al., 2003; Bais et al., 2006). Through these effects, plants can influence other plants that grow later in the same soil, a phenomenon known as "plant-soil feedback" (Van der Putten et al., 2013). Plant-soil feedbacks have been shown to affect succeeding plants positively or negatively (Van der Putten et al., 2013) and frequently influence carbon and nutrient cycling (De Deyn et al., 2008). Consequently, soil feedback effects also influence ecological processes among co-occurring members of a community.

In natural environments, plants exist within communities of con- and heterospecifics that can function as facilitators as well as competitors. Heterospecific plant-soil feedback has been recognized as an important factor influencing the outcome of competition and the degree to which different plants can co-exist (Van der Putten et al., 2013). On the other hand, in agriculture, negative conspecific plant-soil feedbacks necessitate crop rotation and limit replanting of perennial crops, such as fruit trees. One of the most interesting aspects of plant-mediated changes in soil quality is the effect that different soil properties, e.g., soil microbial community, nutrient availability, soil organic matter, water availability, can have on plant secondary metabolism (Magdoff, 1993). While those soil properties have individually been shown to affect plant secondary metabolism and with it, the plants' resistance to herbivores and pathogens (Magdoff, 1993; Meyer, 2000; Chau and Heong, 2005), the link to functional interactions between plants within a community have not been established. Such effects can be interpreted as mechanisms of associational resistance (Barbosa et al., 2009) and thus have a significant impact on our understanding of community dynamics in natural ecosystems, as well as the effects of polycultures and crop rotation, have on agricultural yields.

While both hetero- and conspecific plant-soil feedbacks are considered important to understand community dynamics as well as to inform sustainable and efficient agricultural practices, the underlying mechanisms are poorly understood (Van der Putten et al., 2013). Most studies in this direction have focused on the interactions between wild plant species (Van der Putten et al., 2013; Dias et al., 2014; Detheridge et al., 2016) with only a few studies done on cultivated plants (Ma et al., 2017). However, due to the increased interest in sustainable agriculture, a better understanding of the complex factorial relationships in plantsoil feedbacks has become a major pillar of the new paradigm of ecological intensification.

Ecological intensification uses biological understanding of communities to minimize or replace external inputs to restore ecosystem functions in agro-ecosystems and thereby increase yields (Petersen and Snapp, 2015). This new framework represents a promising way to increase agricultural yields to feed the growing global population while reducing the current negative environmental impacts of conventional agriculture (Bommarco et al., 2013; Garibaldi et al., 2016). Ecological intensification can be realized through regenerative agricultural practices such as permaculture, conservation tillage, cover crops, and intercropping that are often found to revitalize soil and biodiversity (Sherwood and Uphoff, 2000; Lacanne and Lundgren, 2017; Reiss and Drinkwater, 2018). The increase in soil organic matter associated with such practices can affect both chemical and physical soil properties including soil structure, diversity, and activity of soil organisms as well as nutrient availability, which can in turn affect plant growth, quality and productivity (Sherwood and Uphoff, 2000), as well as plant tolerance and resistance to pests and diseases (Eigenbrode and Pimentel, 1988; Chau and Heong, 2005; Ramesh et al., 2005; Atijegbe et al., 2014). It also reduces chemical inputs such as fertilizers and pesticides leading to higher profits for farmers (Lacanne and Lundgren, 2017) and reduced negative effects on ecosystems and people.

One such ecological intensification practice, the pushpull technology, is designed to manage biodiversity through companion cropping in order to control various pest species. In East Africa, push-pull is very successfully used to control stem-boring insect pests and parasitic weeds in cereal crops (Cook et al., 2007; Khan et al., 2010, 2012, 2016; Pickett et al., 2014). For this specific application, the currently proposed pest control mechanism involves attracting stem-boring pests with "pull" plants (e.g., Napier grass), whilst driving them away ("push") from the main crop using an intercrop (e.g., Desmodium spp., Fabaceae) (Figure 1). The repellency and attraction of these "push" and "pull" plants are thought to be mediated by constitutive emission of repellent and attractive volatile semiochemicals, respectively. However, the system has already been shown to have ecological and socio-economic emergent properties that go far beyond the effects on efficient insect pest control. Chemicals released by the roots of one group of push plants, Desmodium spp., induce abortive germination of parasitic Striga weed, providing very effective control of this noxious weed. The companion plants provide high-value animal fodder, facilitating milk production. Most important to the thesis of this study, Desmodium intercropping improves soil fertility through nitrogen fixation and increased soil organic matter content and mitigates erosion by anchoring soil matter to the field (Khan et al., 2016).

Here, we address the question if improved soil properties when using the push-pull technology also have an effect on the crop plants' resistance to insect herbivores. This question is important from an applied perspective but also uses an agricultural system to study the basic mechanisms underlying soil-mediated associational resistance. While characterizing soil quality-mediated effects generally as emergent properties of functional intercropping in the push-pull system, we hypothesized that soil quality altered through the intercropping technology affects plant resistance to herbivores and so 

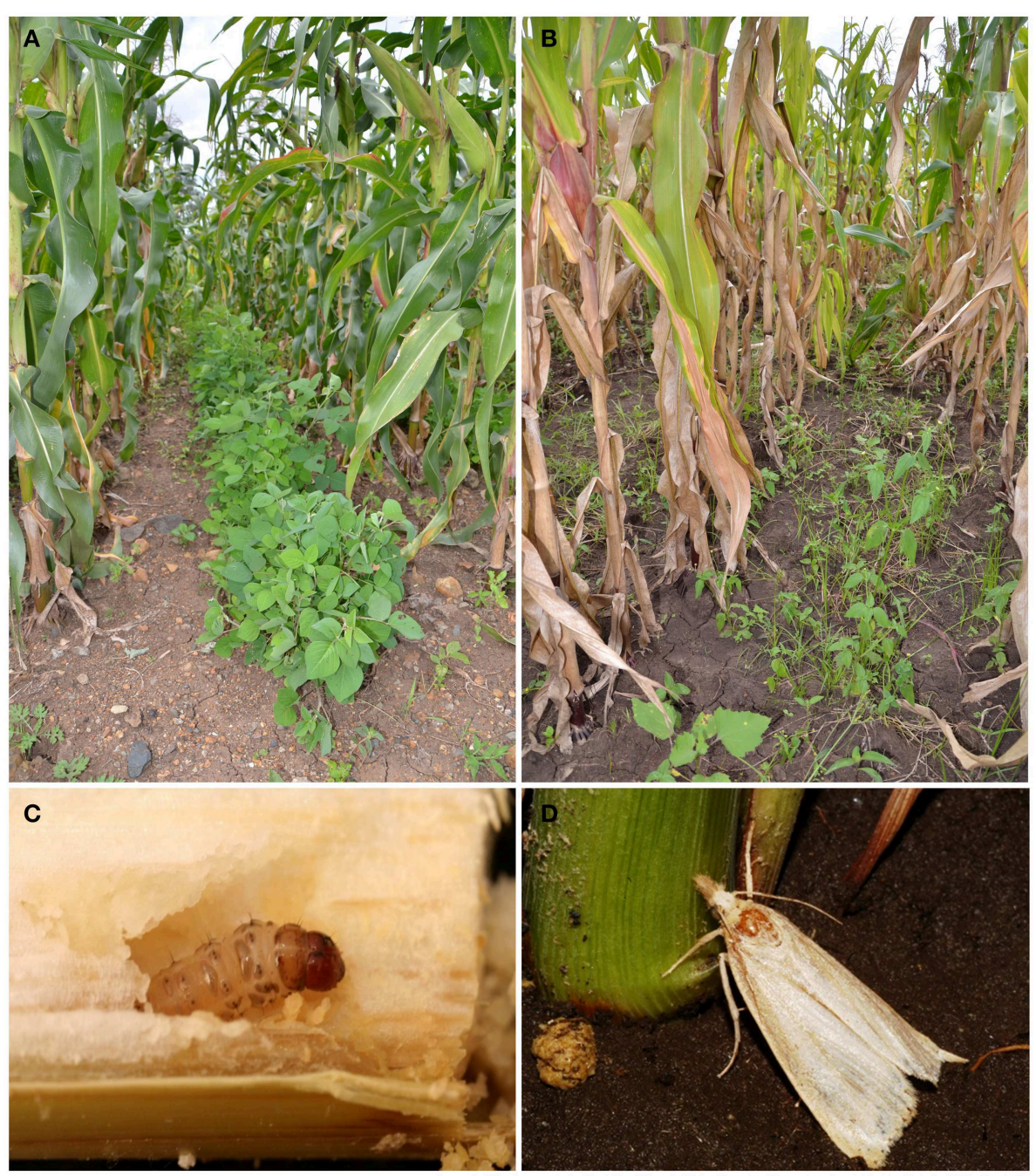

FIGURE 1 | The Push-Pull cropping system. (A) Push-Pull maize (Zea mays) field with green-leaf desmodium, Desmodium intortum, in the undergrowth as the push companion crop. The pull crop is not shown in this image. (B) Conventional maize field with weeds in the undergrowth. The push-pull cropping system is efficient in controlling stem-boring Lepidoptera, such as Chilo partellus whose larvae (C) start feeding on the leaves before boring into the stem with usually fatal effects to the plant. (D) Adult Chilo partellus moth.

constitutes an additional mechanism for push-pull-mediated pest resistance. Therefore, we measured five variables for maize plants planted in both push-pull and non-push-pull conditioned soil: (1) plant growth rate; (2) constitutive volatile emission; (3) stemborer moth oviposition preference; (4) stemborer larval feeding; and (5) production of non-volatile secondary defense metabolites. We discuss the observed effects in the light of ecological concepts, such as emergent properties of species interactions and as mechanisms of associational resistance that result from a functional neighborhood.

\section{MATERIALS AND METHODS}

\section{Study Site}

The study was conducted in 2017 at the Thomas Odhiambo Campus, Mbita Point ( $0^{\circ} 25^{\prime} \mathrm{S}, 34^{\circ} 12^{\prime} \mathrm{E}, 1,200 \mathrm{~m}$ above sea level), a field station of the International Centre of Insect Physiology and Ecology (ICIPE) located on the shores of Lake Victoria in Western Kenya. Soil samples were collected from 11 smallholder farms, both from companion cropping push-pull fields and fields with maize monocultures (non-push-pull) within the same farm. Apart from the cropping system, the farms experienced similar agronomic management conditions with no fertilizer or pesticide applications. Minimum tillage was practiced in all farms for weed control, so that ground cover between maize plants was comparable between monocultures and push-pull plots. However, in push-pull fields, the ground was predominantly covered by Desmodium spp.: green leaf desmodium [Desmodium intortum (Mill.) Urb.] and silverleaf desmodium [Desmodium uncinatum (Jacq.) DC.]. The sampled farms had been under the push-pull and monoculture cropping systems for different years ranging from 2 to 20 years. Soil samples were collected 
when the maize crops were at the late vegetative growth stage being $4-5$ weeks old. Soil sampling was done by randomly taking 10 samples per field up to a depth of $10 \mathrm{~cm}$ between rows of plants. In push-pull fields, samples were taken roughly midway between the maize rows and Desmodium rows, and in control fields samples were taken at a similar distance from maize plants. The soil samples from each field were mixed in separate bags and then transported by car to the laboratory. The soil was used for planting in the screenhouse within $48 \mathrm{~h}$. Predominant soil types in the sampled farms were nitisols and vertisols, which are also the predominant soil types in the Lake Victoria Basin in Kenya (Andriesse and van der Pouw, 1985). Of the sampled farms, six were of the nitisol while five were of the vertisol soil types. Nitisol soils are inherently fertile soils with high nutrient content and deep permeable structure with significant accumulation of clay and a blocky aggregate structure. On the other hand, vertisol soils are dark in color with a wide range of structure from granular to hard, compact and massive structure with moderately variable organic matter content (1-6\%) (Probert et al., 1987).

\section{Plants}

"Sc Duma 43" maize seeds, a common maize variety grown by farmers in Western Kenya, were obtained from Agri-Seedco Ltd, Nairobi, Kenya. The seeds were planted individually in five-liter pots filled with soil collected from the smallholder farms within $48 \mathrm{~h}$ after soil collection in an insect-proof greenhouse under natural conditions $\left(25^{\circ} \mathrm{C}, 65 \% \mathrm{RH} ; 12 \mathrm{~L}: 12 \mathrm{D}\right)$. Four replicates for each farm and soil conditioning type (push-pull or non-pushpull) were planted. To prevent cross-contamination of the soil, gloves were used when handling soil from different fields and also when taking the measurements as well as shoot and root tissues. Seedlings were used for all measurements when they were 3 weeks old.

\section{Insects}

Spotted stemborer (Chilo partellus) (Swinhoe) (Lepidoptera: Crambidae) is a serious pest of gramineous crops in Asia and Africa with the larvae being the injurious stage (Kfir et al., 2002). Mating of the moths occur on the night of eclosion and the female moths are ready to oviposit the following night (Päts, 1991). In the field, moths oviposit mostly on young (3-4 weeks old) maize plants (Kfir et al., 2002). Chilo partellus moths and larvae (Figures 1C,D) used in the experiments were obtained from the insect mass rearing unit of ICIPE-Thomas Odhiambo campus, Mbita point. The initial colony originated from larvae collected from smallholder sorghum fields. The larvae were reared on a maize-based semi-synthetic diet under laboratory conditions at $24 \pm 3^{\circ} \mathrm{C}, 70 \pm 5 \% \mathrm{RH}, 12 \mathrm{~L}$ : 12D (Ochieng et al., 1985). To maintain field-relevant behavioral characteristics and avoid genetic decay, the mass-reared colony is infused with field-collected insects every 3 months. One day old moths from the same age-cohort were used in the experiments. They were allowed to mate randomly in a cage for $24 \mathrm{~h}$ after emergence.

\section{Experiment I: Plant Growth}

Maize plants grown in soil obtained from push-pull companion cropping and maize monoculture (non-push-pull) fields were monitored for 3 weeks and plant height was measured from the soil line to the arch of the uppermost leaf that was halfway emerged from the whorl 14 and 21 days after planting in all 88 plants. Twenty-one days after planting, the plants were divided into two sets, each set containing four replicates from each farm and two replicates for each treatment (push-pull vs. non-push-pull). One set of plants was kept intact and used for the oviposition experiment. The other set was used for volatile collection and analysis of non-volatile secondary metabolite production. For the latter, $\sim 0.20 \mathrm{~g}$ of leaf and $0.30 \mathrm{~g}$ of root tissue were excised from the plants immediately after the volatile collections and processed for secondary metabolite analysis and a larval feeding bioassay. The remaining shoot and roots of the excised maize plants were measured for fresh weight through destructive sampling. Multivariate analysis (MANOVA) with two predictor variables was used for the analysis of height data on the maize plant growth rate over the 3-week period, with companion cropping technology (pushpull vs. non-push-pull), soil type, and the interaction between the cropping system and soil type of the farm as the main predictors. Linear models with square root transformation were used to analyze data on maize plant biomass (shoot and root weight). Individual farm identity was treated as a random factor to account for the four non-independent replicates per farm. All the data analysis was done using R3.4.2 software (R Development Core Team, 2017).

\section{Experiment II: Two-Choice Oviposition Preference}

This experiment was conducted to determine female Chilo partellus' oviposition preference between maize plants grown in push-pull and non-push-pull soils. Two-choice tests were conducted in $185 \mathrm{~cm}$ long $\times 60 \mathrm{~cm}$ wide $\times 60 \mathrm{~cm}$ high oviposition cages covered by a fine white cloth. Two potted maize plants, each grown in either push-pull or non-pushpull soil obtained from the same farm were placed on the opposite side of the cage. Five naive gravid moths were introduced into the cage and a wad of wet cotton wool was placed in the center between the plants for the moths' hydration. The moths were allowed to oviposit on the plants for $48 \mathrm{~h}$ under natural conditions of 12L: 12D. Afterward, the number of egg batches and number of eggs per egg batch on each maize plant were counted under a light microscope at 6.5X. Four plants from each of the 11 farms were used in this experiment for a total of 44 choice tests. Generalized linear models with a Poisson distribution and observationlevel random effects (OLRE) to cater for overdispersion in data (Harrison, 2014) were used for the analysis of the twochoice oviposition preference test. The number of egg batches, as well as number of eggs oviposited per plant, were used as response variables, while soil conditioning by push-pull and non-push-pull, soil type and the interaction of the two factors were used as predictors. Individual farm identity was treated as a random factor to account for the two non-independent replicates per farm. Data was analyzed using R3.4.2 software (R Development Core Team, 2017). 


\section{Experiment III: Larval Feeding Assays}

In order to assess the extent of $C$. partellus larval feeding on maize plants grown in different cropping system soils, we performed both choice and no-choice feeding tests. Leaf discs $(15 \mathrm{~mm}$ diameter) were cut from the second youngest fully expanded maize leaves of plants grown in different soils. In the no-choice test, one piece of the leaf disc was placed in a $30 \mathrm{ml}$ small cup halfway filled with agar to maintain moisture. Ten unfed neonate larvae were then placed on each leaf disc. The cups were then sealed, with a slit in the lid to allow air in. The larvae were left to feed on the leaf discs for $24 \mathrm{~h}$. Leaf discs were then photographed and the area eaten by the larvae was measured using ImageJ (Schneider et al., 2012). A total of 44 plants were used with four plants from each farm. For the choice tests, two leaf discs, each from a maize plant grown in push-pull and non-push-pull soil from the same farm were placed into a $9 \mathrm{~cm}$ diameter Petri dish on the opposite sides. Twenty unfed neonate larvae were then placed at the center of the Petri dish. The Petri dishes were then covered with a lid and sealed with parafilm to prevent the larvae from escaping. The larvae were allowed to feed for $24 \mathrm{~h}$. Thereafter, the leaf discs were photographed and the area consumed in each leaf disc was measured using ImageJ (Schneider et al., 2012). Four plants from each of the 11 farms were used. Preference was indicated for the maize leaf disc with the largest area consumed. In no-choice larval feeding assay, linear models with square root transformation were used to analyze the data. The leaf area consumed by the larvae was used as response variable, while the cropping system, soil type, and the interaction of the two factors were used as predictors. Individual farm identity was treated as a random factor to account for the four non-independent replicates per farm. In the choice larval feeding assay, MannWhitney U (Wilcoxon rank-sum) test was used to compare the feeding damage on each leaf. The use of leaf discs, rather than intact plants allowed to control for environmental factors that could have affected caterpillar feeding even though this might have compromised on specific plant metabolic changes. Data was analyzed using R3.4.2 software (R Development Core Team, 2017).

\section{Experiment IV: Volatile Organic Compounds (VOCs) Collection}

Headspace sampling (Agelopoulos et al., 1999) was used to collect volatile organic compounds from whole maize plants grown in soil from push-pull and non-push-pull fields. Volatiles were collected from these plants for a period of $8 \mathrm{~h}$ both during the day and night. The night volatiles collection started on the first hour of scotophase while day volatiles collection started on the first hour of the photophase. The whole maize seedling was enclosed in polyethyleneterephthalate (PET) bags $(3.2 \mathrm{~L}$, $\sim 12.5 \mathrm{~mm}$ thickness) heated to $150^{\circ} \mathrm{C}$ before use. Volatiles were collected by pulling air through charcoal adsorbent traps (ORBO-32, Supelco, Bellefonte, PA, USA) at $200 \mathrm{ml} \mathrm{min-1,} \mathrm{using}$ a $12-\mathrm{V}$ vacuum pump (GAST; Gast Manufacturing Inclusive, Benton Harbor, MI, USA). Volatiles were also collected from pots filled with soil with no maize plant growing on it and an empty PET bag to serve as background controls. Chemical compounds bound to the ORBO-32 traps were eluted with
$300 \mu \mathrm{l}$ dichloromethane (Sigma-Aldrich, St. Louis, MO, USA). Chemical analysis of the trapped compounds was done by GC-MS on a Varian Saturn 2200 GC/MS/MS with a CP-8400 Autosampler, using an Agilent GC Column (DB-WAX, $30 \mathrm{~m}$, $0.25 \mathrm{~mm}$ ID, $\mathrm{DF}=0.25$ ). Chemical compounds were identified by comparing retention times and mass spectra with those of authentic standards and previously confirmed NIST library hits (Tamiru et al., 2011). The amount of each specific compound was calculated by integrating the peak areas of individual compounds and normalizing by the area of the internal standard, tetraline (Sigma-Aldrich, St. Louis, MO, USA). The relative peak area of each specific compound was standardized to the weight of the leaf tissue used in the volatile trapping. Volatile compounds that were present in the soil and bag controls were excluded from the analysis. We tested the effect of the cropping system, soil type, and the interaction between cropping system and soil type on the composition and quantity of maize volatile organic compounds using permutational multivariate analysis of variance (PERMANOVA; 999 permutations; adonis2 in vegan package) (Anderson, 2001). The farms were treated as strata in the PERMANOVA analysis to account for the random effect. Pairwise comparison between the two soil types was done using pairwiseAdonis (Arbizu, 2017). Shannon diversity index of the whole volatile organic composition in the maize plants grown in the soil from the different cropping systems was determined using vegan package (Anderson, 2001). Data analysis was carried out using R3.4.2 software (R Development Core Team, 2017).

\section{Experiment V: Non-volatile Secondary Metabolites Analysis}

In order to assess the effects of different cropping system soils on secondary metabolism, we analyzed leaves and root tissues for the non-volatile secondary metabolites mainly benzoxazinoids and phenolics. We excised three leaf discs $(\sim 0.20 \mathrm{~g}$ on average) and root tissue $(\sim 0.30 \mathrm{~g}$ on average). The plant tissue was put into $2 \mathrm{ml} \mathrm{screw-top} \mathrm{FastPrep}{ }^{\circledR}$ vials and submerged in $1 \mathrm{ml}$ of $50 \%$ HPLC grade methanol extraction buffer. The samples were stored in $-20^{\circ} \mathrm{C}$ awaiting further processing. The root and leaf tissue were extracted by adding one customized scoop ( $0.9 \mathrm{~g})$ grinding beads (BioSpec ${ }^{\circledR}$, Zirconia/Silica $2.3 \mathrm{~mm}$ ) to each sample and the tissue homogenized using FastPrep ${ }^{\circledR}$ tissue homogenizer (MP Biomedicals ${ }^{\circledR}$, Solon, Ohio, USA) at $6 \mathrm{~m} / \mathrm{s}$ for $60 \mathrm{~s}$. The homogenized tissue was then centrifuged at $4^{\circ} \mathrm{C}$ for $15 \mathrm{~min}$ at 14,000 rpm (Eppendorf centrifuge with 30 tubes, fixed angle rotor: $20,800 \times \mathrm{g}$ ). Approximately $300-500 \mu \mathrm{L}$ of the supernatant was carefully transferred into HPLC vials. Fifteen microlitre of the supernatant was analyzed for secondary metabolites using high performance liquid chromatography (HPLC) (Agilent 1100 HPLC with Diode Array Detector) with a Gemini C18 reversephase column $(3 \mu \mathrm{m}, 150 \times 4.6 \mathrm{~mm}$, Phenomenex, Torrance, CA, USA). The elution system consisted of aqueous $0.25 \%$ phosphoric acid $\left(\mathrm{H}_{3} \mathrm{PO}_{4}\right)$ and acetonitrile $(\mathrm{ACN})$ which were pumped through the column at a rate of $0.7 \mathrm{ml} / \mathrm{min}$ with increasing concentrations of acetonitrile: $0-5 \mathrm{~min}, 0-20 \% \mathrm{ACN}$; $5-35 \mathrm{~min}$, $20-95 \%$ ACN. The chromatograms were aligned using the $\mathrm{R}$ package Alsace (Wehrens, 2018). Metabolites were identified to compound class using their UV spectra, confirmed by their 


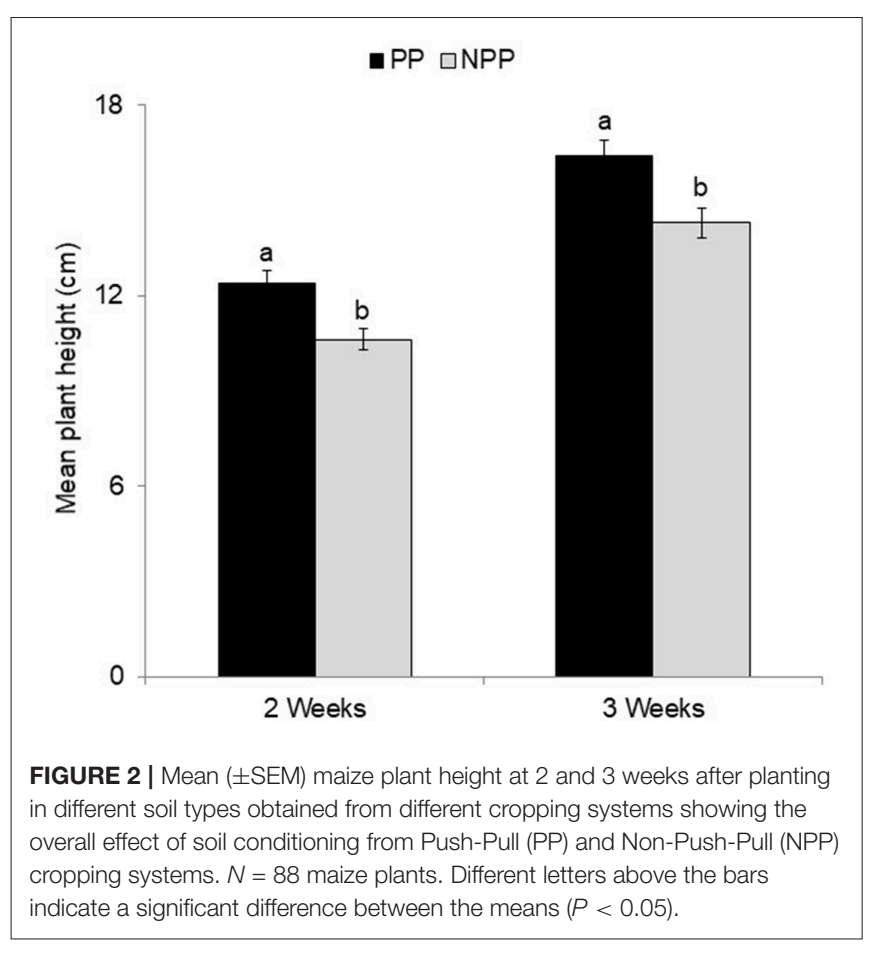

authentic standards and quantified by their signal intensities. The effect of the cropping system, soil type, and the interaction between cropping system and soil type on the composition and quantity of maize secondary metabolites was tested using permutational multivariate analysis of variance (PERMANOVA; 999 permutations; adonis2 in vegan package) (Anderson, 2001). The farms were treated as strata in the PERMANOVA analysis. Shannon diversity index of the whole secondary metabolites composition in the maize plants grown in the soil from the different cropping systems was determined using vegan package (Anderson, 2001). All the data analysis was done using R3.4.2 software (R Development Core Team, 2017).

\section{RESULTS}

\section{Experiment I: Maize Plant Growth}

Maize plants grown in soil collected from fields with push-pull companion cropping had significantly higher growth rates in terms of plant height compared to those grown in soil from monoculture fields (Figure 2). Cropping system $\left[F_{(1,74)}=16.00\right.$, $P \leq 0.001$, Figure 2, Supplementary Figure 1], but not soil type $\left[F_{(1,74)}=2.69, P=0.105\right]$, or the interaction of the two factors $\left[F_{(1,74)}=0.01, P=0.903\right]$ affected plant height. We observed no difference in the shoot and root weight between maize plants grown in the soil from push-pull fields compared to those grown in the soil from non-push-pull monoculture fields (dry shoot weight: $\mathrm{PP}=2.494 \pm 0.313, \mathrm{NPP}=1.982$ \pm 0.173 ; dry root weight: $\mathrm{PP}=1.634 \pm 0.171, \mathrm{NPP}=1.475$ \pm 0.139) (Supplementary Table 1). There was no treatment effect on shoot: root ratios in both treatments $(\mathrm{PP}=1: 0.655$; $\mathrm{NPP}=1: 0.744)$.

\section{Experiment II: Oviposition Preference}

When moths were given a choice to oviposit on maize plants grown in soil from push-pull or non-push-pull fields, we could not detect any differences in oviposition preference in terms of the number of egg batches or total number of eggs laid (Supplementary Table 2; Supplementary Figure 2).

\section{Experiment III: Larval Feeding}

Neonate C. partellus larvae generally consumed larger leaf area of leaf discs from maize plants grown in soil from non-push-pull fields compared to those grown in soil from push-pull fields in the no choice assay (Figure 3). The companion cropping pushpull system, regardless of the soil type or the interaction of the two factors affected the feeding behavior of the larvae in nochoice feeding assay [Push-pull cropping effect: $F_{(1,40)}=6.665$, $P=0.014$; soil type effect: $F_{(1,40)}=0.353, P=0.556$; pushpull*soil type interaction effect: $\left.F_{(1,40)}=1.083, P=0.304\right]$. In the choice test, there was no difference in the amount of leaf material consumed by larvae between leaf discs from maize plants from non-push-pull fields $(11.38 \pm 3.09)$ compared to maize plants grown in soils from push-pull fields $(8.13 \pm 2.73)(P=0.185$, $n=21)$.

\section{Experiment IV: Volatile Organic Compounds (VOC) Emissions}

Both qualitative and quantitative differences in volatile profiles were observed in maize plants grown in soil conditioned by pushpull companion cropping and those grown in soil conditioned by non-push-pull monocultures (Figure 4). Daytime VOC collections resulted in quantifiable amounts, while the night trappings had only trace amounts of the volatiles and were thus not used in the analysis. Overall, the maize volatile organic compound emission was affected by the soil conditions resulting from the companion cropping push-pull system, soil type, and the interaction between the companion cropping pushpull and the soil type, with maize plants grown in vertisol soils emitting higher quantities of volatile compounds (Table 1). Chemical compounds including $\beta$-pinene, limonene, $(E)$ 4,8-dimethyl-1,3,7-nonatriene, $\beta$-caryophyllene, $\beta$-farnesene, $\alpha$ humulene, germacrene $\mathrm{D}$, and $(E, E)-4,8,12$-trimethyl-1,3,7,11tridecatetraene which maize plants are known to increasingly emit in response to herbivore attack (Tamiru et al., 2011) were emitted in elevated levels in maize plants grown in the soil from push-pull fields compared to those grown in soil from maize monocultures (Figure 4). The overall composition and abundance of the VOCs was more diverse in the soil conditioned by push-pull companion cropping compared to the one conditioned by non-push-pull monocultures [Shannon diversity index; $F_{(1,40)}=22.234, P \leq 0.001$ ], with plants grown in push-pull conditioned soil emitting more diverse and higher quantities of volatile compounds.

\section{Experiment V: Non-volatile Secondary Metabolite Production}

Maize grown in soil obtained from push-pull fields produced higher amounts of overall secondary metabolites compared to those grown in soil from non-push-pull monocultures 


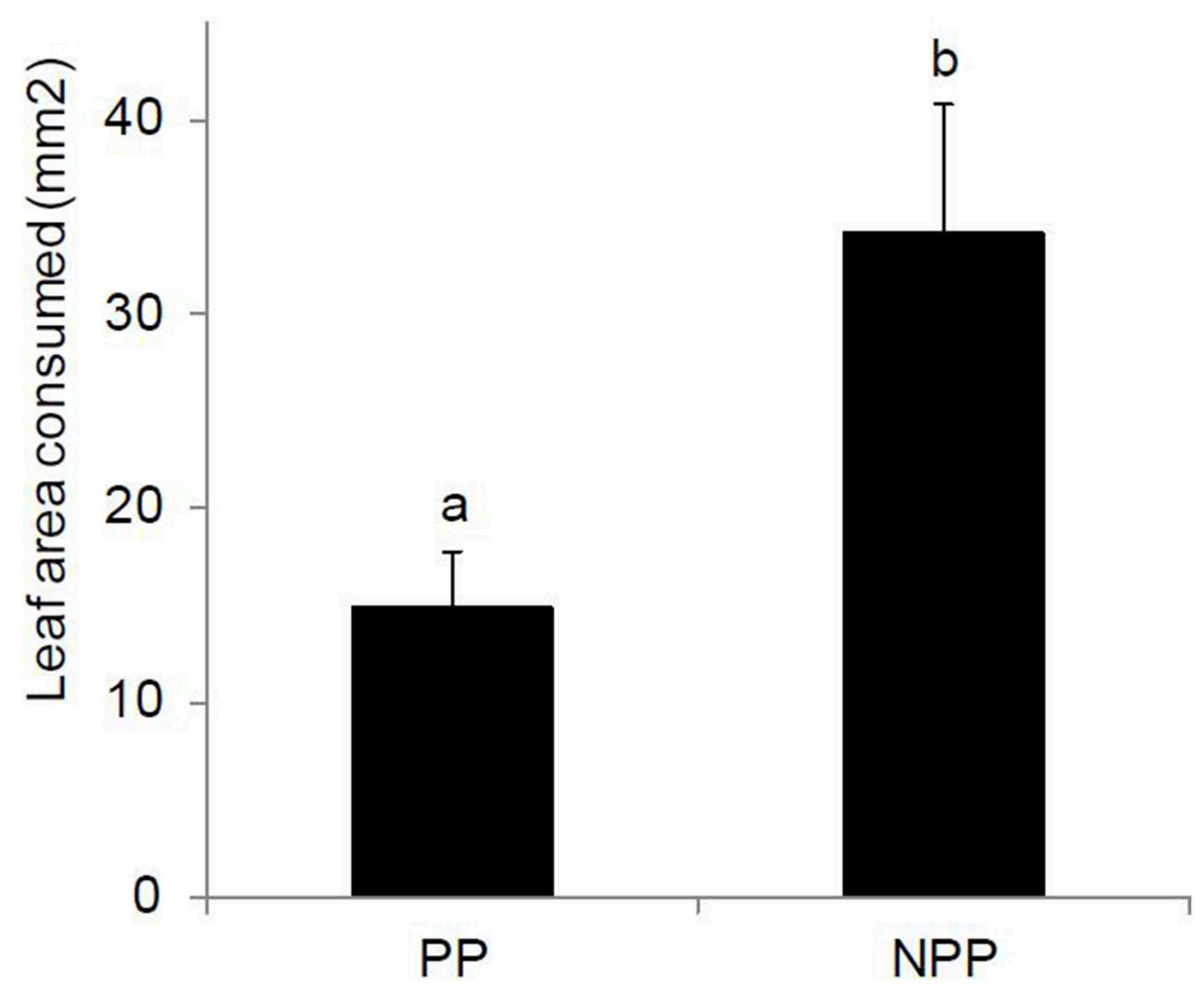

FIGURE 3 | Mean ( \pm SEM) maize leaf area consumed by first instar Chilo partellus larvae in a no-choice experiment on plant material grown in soil from Push-Pull (PP) and Non-Push-Pull (NPP) cropping systems. Different letters above the bars indicate significant differences between the means $(P<0.05)$. $N=44$ maize plants.

including known maize defense metabolites like 2,4-dihydroxy7-methoxy-2H-1,4-benzoxazin-3(4H)-one (DIMBOA), 6-methoxy-benzoxazolin-2-one (MBOA), and p-coumaric acid (Table 2; Figure 5). The composition and quantities of these metabolites were different in the root tissue while the composition in the shoot tissue was not significantly different (Table 2). The soil type also affected the secondary metabolite production in both the leaf and root tissue with more metabolites being produced in vertisol soil (Table 2). The diversity of secondary metabolites was higher in maize plants grown in soil conditioned by push-pull cropping compared to non-push-pull monocultures for the root tissue [Shannon diversity index: $\left.F_{(1,40)}=21.373, P=0.001\right]$.

\section{DISCUSSION}

Soil conditioning by push-pull intercropping fundamentally affected plant growth, secondary metabolism, and resistance to a major herbivore, Chilo partellus. The experimental design links improved plant growth as well as increased herbivore resistance to the soil conditions affected by intercropping alone. There are several interesting aspects of these results. First, our experiments establish increased plant growth and herbivore resistance as an emergent ecological property of functional intercropping practiced with the push-pull technology. Second, the results suggest soil-mediated indirect effects on plant secondary metabolism and resistance as a mechanism mediating plant associational resistance. Third, and from a more applied perspective, the results provide soil-mediated resistance to herbivores as an additional and/or alternative mechanism of action that makes the push-pull technology such an efficient pest control system. We discuss our results in light of these three concepts and previous publications.

\section{Soil-Mediated Emergent Properties of Companion Cropping}

The push-pull companion cropping had a positive soil-mediated effect on maize growth and resistance, compared to the soil conditioned by the monoculture cropping system. The Desmodium spp. plants grown between maize in the pushpull system are nitrogen-fixing legumes with especially high efficiency to enrich the soil with nitrates (Harrison and Bardgett, 2010; Kremen and Miles, 2012). In addition, although cut back seasonally, Desmodium is grown as permaculture so that leaf and root biomass from this intercrop usually remains in the fields, thus contributing to organic matter accumulation. Desmodium also acts as a cover crop preventing soil degradation and controlling weeds. The positive effects of nitrogen fixation and organic matter accumulation on plant growth and yield have long been recognized, which is why legumes are often intercropped or rotated with other crops (Drinkwater et al., 1998). 


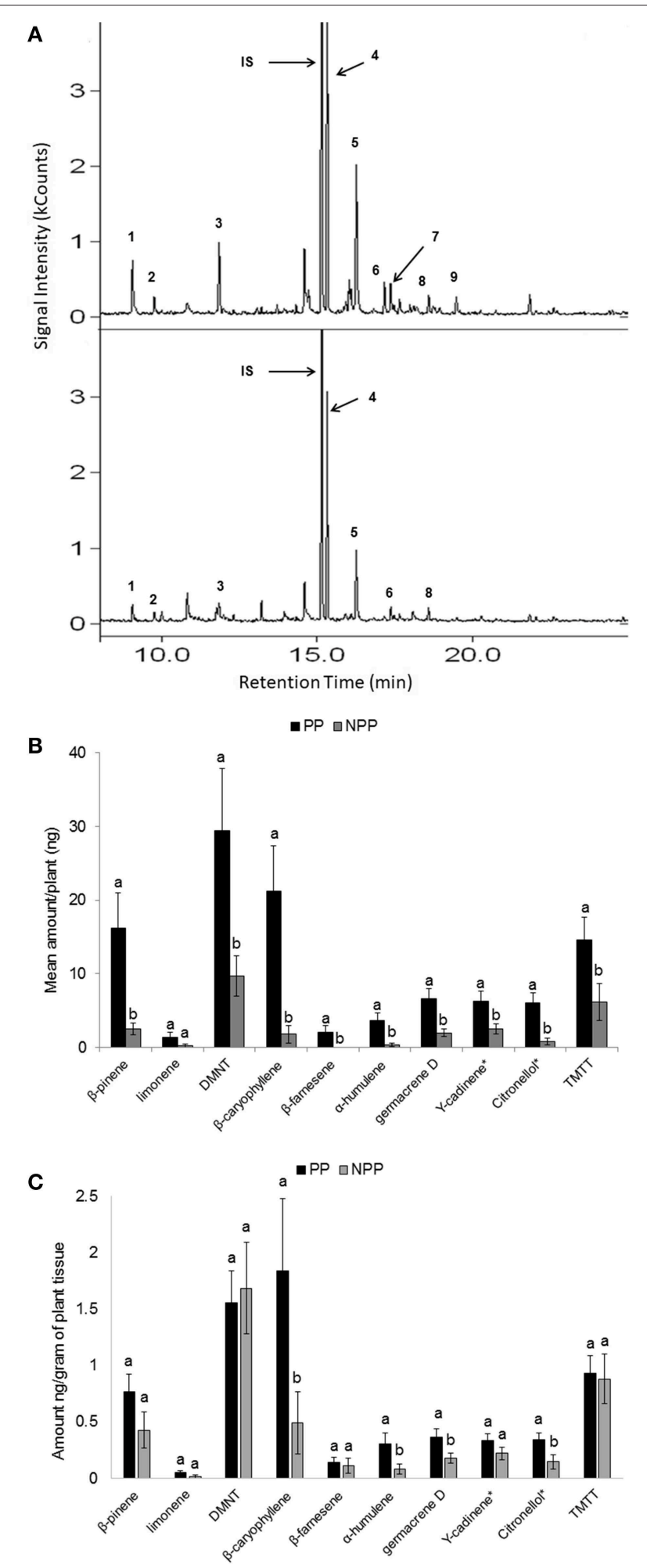

FIGURE 4 | Volatile compounds emitted by maize plants grown in soil obtained from Push-Pull (PP) companion cropping and Non-Push-Pull (NPP) monoculture fields: (A) Representative gas-chromatograph profiles of plants grown in soil from PP and NPP fields. Numbers designate key volatile compounds: 1. $\beta$-pinene, 2. limonene, 3. (E)-4,8-dimethyl-1,3,7-nonatriene

(Continued)
FIGURE 4 | (DMNT), 4. 1,6-Octadien-3-ol,3,7 dimethyl-, 5. $\beta$-caryophyllene, 6. $\beta$-farnesene, 7. $\alpha$-humulene, 8. germacrene $D, 9$. $(E, E)$-4,8,12-trimethyl-1,3,7,11-tridecatetraene (TMTT), IS = Internal Standard (tetralin). (B) Mean ( \pm SEM) quantities of selected volatiles emitted per plant from plants grown in soil from PP and NPP fields. (C) Mean ( \pm SEM) quantities of selected volatiles emitted in nanogram/gram from plants grown in soil from PP and NPP fields. Different letters above the bars indicate a significant differences between the means $(P<0.05)$.

Continuous monocultures are frequently reported to adversely impact their biotic and abiotic soil environments in ways that ultimately reduce their own growth (Bever et al., 1997; Van der Putten et al., 2013), which is particularly true for maize monocultures (Ewel et al., 1991). Polycultures, in contrast, are more likely to show positive plant-soil feedbacks, because they alter the soil conditions to favor higher total biomass accumulation and yield (Picasso et al., 2008). Negative soil feedbacks may be reduced in polycultures either through the dilution of pathogen density or through the addition of soil nutrients (Van der Putten et al., 2013). This positive feedback allows plant species in polycultures to grow better than plants in monocultures leading to overyielding in mixed plant communities compared to monocultures (Van der Putten et al., 2013). Thus, the positive growth effects in push-pull soil, observed in our study may derive from increased nutrient availability due to nitrogen fixation and soil organic matter accumulation, a healthier soil microbial community, more efficient nutrient uptake because of altered soil chemistry or, most likely, a combination of these factors. Our experiments were not designed to evaluate the relative contributions of each of these potential mechanisms. Future studies should investigate the degree to which push-pull cultivation alters the microbial, chemical, and physical conditions of the soil as well as the nutrition of plants grown in these soils and how such alterations contribute to increased plant growth and resistance as an emergent property of functional intercropping.

Interestingly, the soil-mediated growth effects are further emphasized by another emergent property of the cultivation system, namely increased resistance to major herbivore species through the production of repellent volatiles and larval feeding deterrents. Maize plants grown in soil from the two cropping systems were found to differ qualitatively and quantitatively in their volatile organic compound profiles. Several compounds including $\beta$-pinene, (E)-4,8-dimethyl-1,3,7-nonatriene (DMNT), $\beta$-caryophyllene, $\beta$-farnesene, $\alpha$-humulene, germacrene $\mathrm{D}$, and (E,E)-4,8,12-trimethyl-1,3,7,11-tridecatetraene (TMTT) were emitted in higher quantities by maize plants grown in soil conditioned by push-pull companion cropping compared to those grown in soil conditioned by the monocultures. Maize plants are known to produce such compounds when damaged by herbivore attack (Kollner et al., 2008; Oluwafemi et al., 2011; von Mérey et al., 2013) or upon detection of herbivore eggs (Tamiru et al., 2011, 2012; Mutyambai et al., 2015). These chemical compounds can function to defend maize plants against herbivores either through the deterrence of subsequent 
TABLE 1 | Results of PERMANOVA comparing the effects of push-pull companion cropping technology, soil type, and their interaction on the overall volatile organic compounds composition and quantities produced by maize plant grown in soil conditioned by different cropping systems.

\begin{tabular}{lcccc}
\hline & df & Sum of sqs & $\boldsymbol{F}$ & $\boldsymbol{P}$ \\
\hline Push-pull cropping system & 1 & 0.589 & 2.663 & $\mathbf{0 . 0 2 2}$ \\
Soil type & 1 & 0.462 & 2.22 & $\mathbf{0 . 0 0 1}$ \\
Push-pull cropping system $\times$ soil type & 1 & 0.713 & 3.427 & $\mathbf{0 . 0 1 0}$ \\
Residual & 32 & 6.663 & &
\end{tabular}

Bold values indicate significant difference at $P<0.05$.

TABLE 2 | Results of PERMANOVA comparing the effects of push-pull companion cropping technology, soil type, and their interaction on non-volatile secondary metabolite production and composition in root and leaf tissue of maize plant grown in soil conditioned by push-pull companion cropping and non-push-pull maize monocultures.

\begin{tabular}{lcccc}
\hline Root tissue & df & Sum of sqs & $\boldsymbol{F}$ & $\boldsymbol{P}$ \\
\hline Push-pull cropping system & 1 & 0.424 & 2.901 & $\mathbf{0 . 0 2 4}$ \\
Soil type & 1 & 0.552 & 3.779 & $\mathbf{0 . 0 0 4}$ \\
$\begin{array}{l}\text { Push-pull cropping system } \times \text { soil type } \\
\text { Residual }\end{array}$ & 1 & 0.362 & 2.477 & $\mathbf{0 . 0 4 3}$ \\
Leaf tissue & 40 & 5.838 & & \\
Push-pull cropping system & 1 & 0.266 & 1.274 & 0.164 \\
Soil type & 1 & 0.369 & 1.768 & $\mathbf{0 . 0 2 4}$ \\
Push-pull cropping system $\times$ soil type & 1 & 0.156 & 0.746 & 0.818 \\
Residual & 40 & 8.359 & & \\
\hline
\end{tabular}

Bold values indicate significant difference at $P<0.05$.

moth oviposition (Mutyambai et al., 2014, 2015) or through the attraction of natural enemies (Khan et al., 1997; Tamiru et al., 2011; Mutyambai et al., 2015). In our study, however, no statistically significant difference was detected in the moth oviposition between maize plants grown in soil from push-pull and non-push-pull fields. While this could be attributed to limited sample size, this result could also be an indication for two biological phenomena at play.

First, in previous studies herbivore- or oviposition-induced VOC emissions had been found as factors driving oviposition choices of C. partellus adults (Mutyambai et al., 2014, 2015). The VOC emissions induced by push-pull soil may include some of the same compounds but as a bouquet may not contain the same information for the female moths as herbivore-induced VOCs. Moreover, the effect of push-pull companion cropping on oviposition choices had earlier been attributed to the constitutive emissions from Desmodium spp. (Khan et al., 2010; Pickett et al., 2014), which also include some of the herbivory-inducible compounds. In consequence, the presence of the push-plant or some active elicitation by a herbivore may be necessary for the repellant effect. The remaining question then would be if the soil induction effects function synergistically with the companion crop present or herbivores damaging the plant. Second, and in contradiction to the common paradigm, some studies found preference of adult C. partellus moths to oviposit on previously damaged plants (Kumar, 1986; Ntiri et al., 2018), suggesting some environmental factors influencing decision making or differences in chemical information produced by different plant genotypes. In all of these cases, future research has to focus on the interactions of the factors influencing the generation of chemical information and how this information is processed by adult moths to make oviposition decisions. This naturally extends also into the question in how far prey/host search behavior of natural enemies of the herbivores is affected by the extensive soil-induced changes in chemical signaling observed in this study.

Although plant growth and resistance are commonly predicted to be negatively correlated (Stamp, 2003), biotic inductions can often go counter to the growth and defense tradeoff. For example, biotic induced changes in plant metabolism, such as growth-enhancing microorganism (Fahad et al., 2015) and herbivore-induced overcompensation (Poveda et al., 2010, 2012; Halitschke et al., 2011) frequently link increased growth and resistance to herbivores. Thus, the lack of a clear trade-off between growth and defense in our study can be interpreted as an indication of soil agent-induced specific responses but requires further detailed studies.

Such an association of increased plant resistance and secondary metabolite production with improved soil quality has been observed previously (Howard et al., 2018). One potential underlying mechanism involves soil quality-specific microbe species inducing resistance in both aerial and belowground plant tissues. These microbes may trigger increased defense metabolite production or the emission of volatile organic compounds in associated plants and so influence herbivore choice and performance (Pineda et al., 2010). Evidently, this increased soil- and plant secondary metabolism-mediated resistance to pest herbivores can be characterized as an additional emergent property of push-pull cultivation. In combination with the increased growth, the increased feeding deterrence of pests could be the major drivers of the higher yields observed under pushpull cultivation (Khan et al., 2016).

\section{Soil-Mediated Associational Resistance}

Associational resistance or susceptibility are evident when the likelihood of detection by or the resistance to antagonists, such as herbivores or pathogens, is altered as a function of the association with a neighboring plant within the plant community (Barbosa et al., 2009). While a number of associational resistance mechanisms have been reported, such as plantplant communication, chemical crypsis or optical distraction, soil-mediated mechanisms are less often considered (Barbosa et al., 2009). Nevertheless, there is growing evidence that certain soil attributes can affect plant chemistry in ways that impact defense. For example, nutrient availability (Römheld and Kirkby, 2010) and the presence of certain soil microbes (Pineda et al., 2010) can affect or induce changes in plant secondary metabolism. Moreover, it has been suggested that plant metabolism may be altered in response to chemicals secreted from neighboring plants or even by the direct uptake of chemicals from the neighbors (Howard et al., 2018; Kessler and Kalske, 2018). The identification of the specific mechanisms underlying the soil-mediated increased resistance in maize plants grown in push-pull soils goes beyond the 
A

Root

Shoot

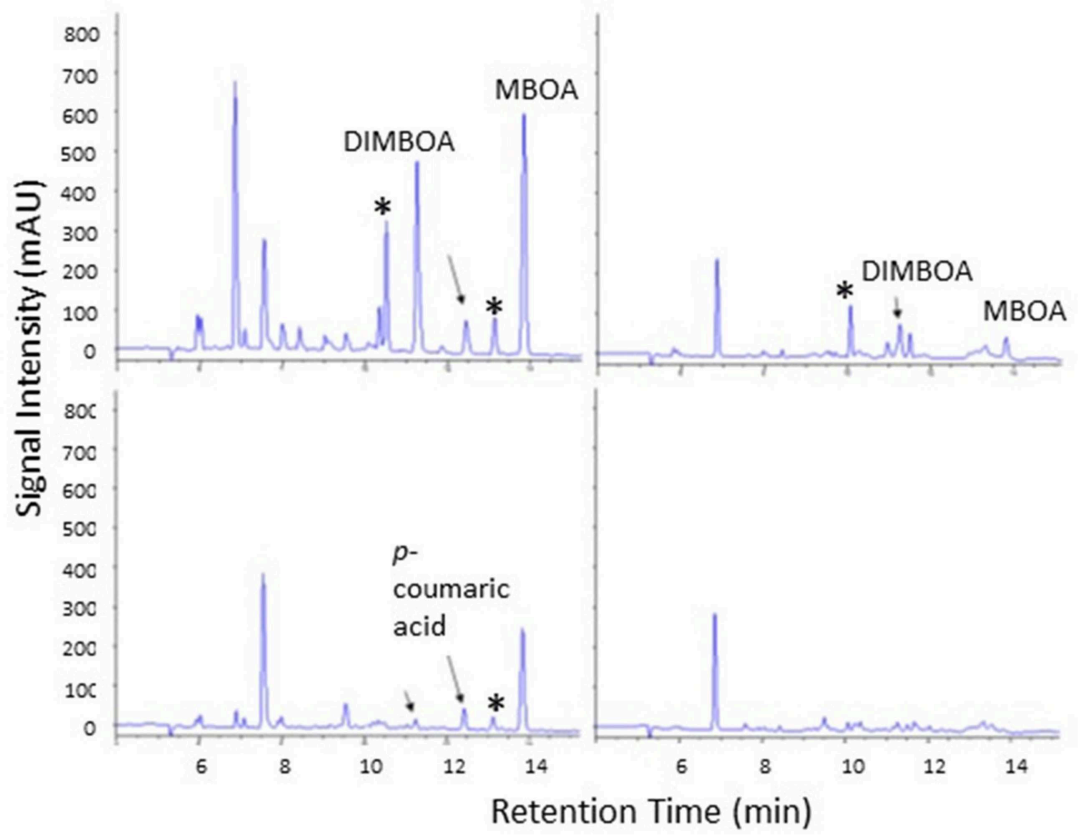

PP

NPP

B

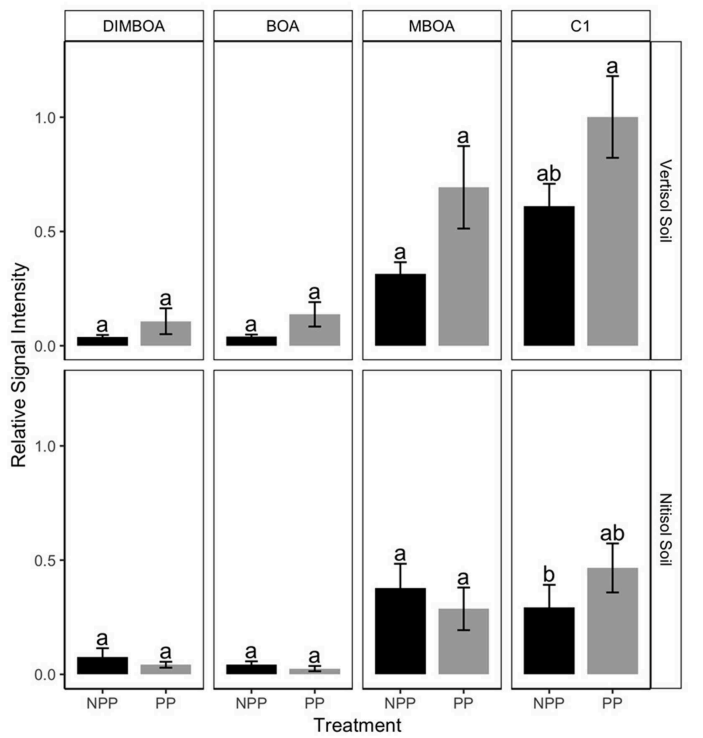

C

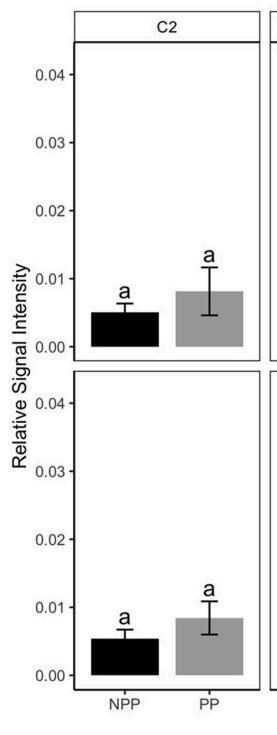

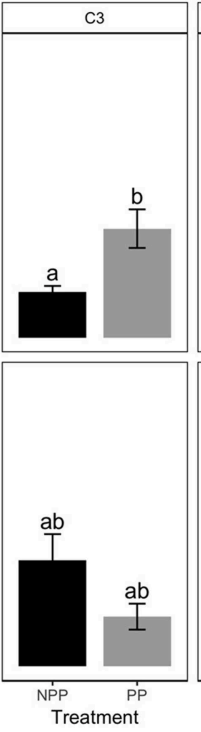

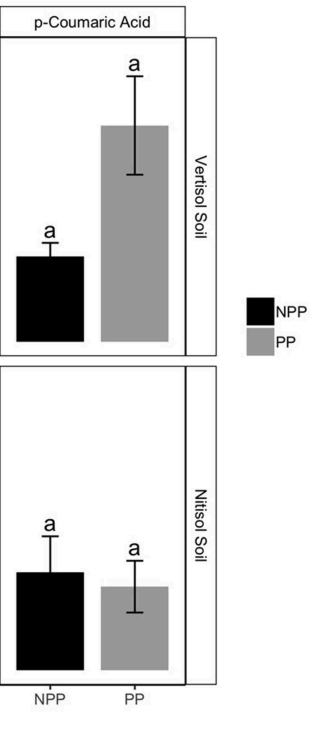

FIGURE 5 | Non-volatile secondary metabolites produced by maize plants grown in soil obtained from Push-Pull (PP) companion cropping and Non-Push-Pull (NPP) monoculture fields: (A) Representative High Performance Liquid Chromatography profiles of non-volatile secondary metabolites from Root and Shoot tissue. (B) Mean ( \pm SEM) quantities of identified benzoxazinoids from root tissue per plant from maize plants grown in soil from PP and NPP fields. (C) Mean ( \pm SEM) quantities of hydroxycinnamic acids from root tissue per plant from maize plants grown in soil from PP and NPP fields. Overall mean abundance of known maize defense metabolites was significantly higher in maize grown in soil conditioned by Push-Pull cropping compared to Non-Push-Pull monocultures $(P \leq 0.001)$. "indicates benzoxazinoid metabolites whose identity has not yet been confirmed using authentic synthetic standards. C1, C2, and C3 represent compounds whose identity was not confirmed with authentic standards. Different letters above the bars indicate a significant difference between the means $(P<0.05)$ of compound production across soil types and cropping system.

scope of this study. However, the clear link established here between soil conditions and changes in secondary metabolite profiles has some fundamental ecological implications. For agricultural systems, functional companion cropping provides a powerful associational resistance tool to boost pest control. For natural systems, our findings suggest a potential state of ideal neighborhood for an individual plant within plant communities to maximize fitness (Barbosa et al., 2009). 
The remarkable alteration of plant volatile emissions, secondary metabolites and the associated reduced larval feeding under push-pull cultivation raises questions about the mechanisms underlying soil-induced differences in plant secondary metabolism and the general functions of such responses. In our experiments, soil condition-dependent VOC emission turned out to be a signature of a general change in plant metabolism. In addition to the increased VOC emissions from plants in push-pull soils, these plants also expressed higher quantities of non-volatile secondary metabolites such as benzoxazinoids and hydroxycinnamic acids compared to the maize plants grown in the soil from monoculture fields. Benzoxazinoids are potent defense compounds with known activity against insect herbivores and pathogens, produced by a number of species in the Poaceae family, including maize (Niemeyer, 1988, 2009; Frey et al., 2009). In our study, increased production of benzoxazinoids and hydroxycinnamic acids in maize grown on push-pull conditioned soil was strongly associated with reduced leaf feeding by $C$. partellus neonates in a no-choice assay. The fact that a significant difference in benzoxazinoids was only detected in root tissue in our study, is likely due to the tissue-specific developmental changes in their production. Younger plants produce higher concentrations than older plants but roots tend to maintain these high concentrations into later growth stages, while the concentrations in the shoots drop over time (Cambier et al., 2000). We still observed a correlation between root benzoxazinoid production and leaf-feeding herbivore performance because root and shoot benzoxazinoid production are highly correlated.

Insect herbivore larval acceptance of the host and subsequent feeding is influenced by plant chemistry among other factors (Sétamou et al., 1993; Awmack and Leather, 2002). The high concentration of defensive compounds in the roots together with the increased emissions of volatile secondary metabolites from the leaves increased direct resistance in the maize plants overall when grown in the soil from the companion cropping system. These changes are likely accompanied by changes in plant primary metabolism that in interaction with the changes in secondary metabolism affect herbivore performance (Kessler and Baldwin, 2002). The metabolic changes we measured in this study are only a small part of the actual changes and merely a proxy for the metabolic reconfiguration of the plant. Because this increased herbivore resistance is mediated by the soil conditions that result from functional intercropping and thus a neighborhood with another plant species, it can be viewed as a form of associational resistance.

\section{Soil-Mediated Resistance to Herbivores as an Additional Mechanism to Push-Pull}

The evidence presented in this study shows that push-pull cultivation alters soil conditions that, in turn, mediate increased direct resistance to herbivores. This raises the interesting question in how far "push" and "pull" as presented in multiple studies are the major or even the mechanism explaining the successful pest control realized through this companion cropping technology. The production of VOCs known to repel ovipositing C. partellus moths while attracting its natural enemies and the direct resistance of plants grown in push-pull-conditioned soils are expected to function as additional mechanisms contributing to the pest-controlling properties provided by the push-pull cropping system.

The push (repellency) effect had previously been suggested to be driven by the constitutive VOC emissions of the intercropped plants, such as Desmodium spp. These plant species produce VOCs released by maize in response to herbivore damage (Pickett et al., 2014), and C. partellus moths avoid previously oviposited plants for oviposition (Mutyambai et al., 2015). Our study suggests that soil conditioning by a neighboring plant can induce increased emissions of the same VOCs that are avoided by ovipositing adult moths in the maize crop itself. Thereby the effect is apparent without the actual presence of the "push"-plant but the effects these plants had on soil conditions, such as soil organic matter, nutrient availability, soil microbial community, and secondary chemistry. While the specific mechanisms still need to be unraveled, all of these factors can potentially influence plant secondary metabolite production (Howard et al., 2018). Functionally, however, the increased emissions of otherwise herbivore-induced VOCs by maize should emphasize any chemical signal coming from the companion plant that repels insect oviposition. The chemical information transferred to the pest is the same and should act additively or synergistically with the repellent effect of the push plants. The lack of a clear avoidance of plants grown in push-pull soil by adult C. partellus moths, despite the much higher defensive VOC emission, may be an indication of such an interactive effect of induced maize VOC emission with that of the Desmodium spp. intercrops in repelling pest insects.

Similarly, the increased production of toxic defensive metabolites, such as benzoxazinoids should also reinforce the push-effect, as well as contributing directly to plant resistance. Thus, the soil-mediated effects of companion cropping on plant resistance found in this study likely represent an additional mechanism through which the push-pull cropping technology successfully controls pest insects. This raises the interesting prospect that the existence of multiple, layered mechanisms serving a similar pest-controlling function, could make the technology more resilient and evolutionarily sustainable. Such layered chemical defenses that could also vary in their relative importance in different habitats, could explain why the technology seems to be robust across many different environments and works consistently over many years, seemingly without the evolution of tolerance to the general pest control strategy. Indeed, the technology has been shown to be effective in controlling different insect species including Spodoptera frugiperda (J. E. Smith), a recent invasive pest in East Africa (Midega et al., 2018). Future research should focus on the context dependency of multiple co-existing chemical defense mechanisms, their functionality, and whether their relative importance differs by environment.

\section{CONCLUSION}

We demonstrate that soil conditioning through companion cropping in an agricultural ecosystem can influence the growth rate and chemical phenotype of maize. These changes in plant metabolism negatively impact insect pest performance by 
suppressing larval feeding. This link between soil condition and plant secondary metabolism represents an emergent property of functional neighborhood, a new mechanism of associational resistance and an additional mechanism through which the push-pull companion cropping system works to manage insect pests and parasitic weeds in agroecosystems. Disentangling the specific mechanisms that link soil properties, such as nutrient availability, soil chemistry, or the soil microbiome and how they affect plant secondary metabolism needs to be the focus of future research. This kind of knowledge will lead to a deeper understanding of how natural plant communities are structured and why they vary over time, and how plant chemical information transfer between interacting organisms can be manipulated to maximize pest control in agricultural systems (Kessler and Kalske, 2018).

\section{AUTHOR CONTRIBUTIONS}

$\mathrm{DM}, \mathrm{KP}$, and $\mathrm{AK}$ conceived the original research idea and design of the study. All authors were involved in the planning and specific design of the experiments. DM conducted and coordinated the experiments. EB, TL, KP, and AK helped with various aspects of the experiments. Data analysis was conducted by $\mathrm{DM}$ and $\mathrm{EB}$. DM and $\mathrm{AK}$ wrote the first

\section{REFERENCES}

Agelopoulos, N. G., Hooper, A. M., Maniar, S. P., Pickett, J. A., and Wadhams, L. J. (1999). A novel approach for isolation of volatile chemicals released by individual leaves of a plant in situ. J. Chem. Ecol. 25, 1411-1425. doi: 10.1023/A:1020939112234

Anderson, M. J. (2001). A new method for non-parametric multivariate analysis of variance. Aust. Ecol. 26, 32-46. doi: 10.1046/j.1442-9993.2001. 01070.x

Andriesse, W., and van der Pouw, B. J. A. (1985). Reconnaissance Soil Map of the Lake Victoria Basin Development Authority Area Western Kenya. The Netherlands Soil Survey Institute. Available online at: http://esdac.jrc.ec. europa.eu/images/Eudasm/Asia/images/maps/download/MY3004_1SO.jpg

Arbizu, M. (2017). Pairwiseadonis: Pairwise Multilevel Comparison Using Adonis. R Package Version 0.0.1. Vienna: R Foundation for Statistical Computing. Available online at: https://github.com/pmartinezarbizu/pairwiseAdonis (accessed on January 22, 2019).

Atijegbe, S. R., Nuga, B. O., Lale, N. E. S., and Ruth, N. (2014). Effect of organic and inorganic fertilizers on Okra (Abelmoschus esculentus L. Moench) production and incidence of insect pests in the humid tropics. J. Agri. Vet. Sci.7, 25-30. doi: 10.9790/2380-07432530

Awmack, C. S., and Leather, S. R. (2002). Host plant quality and fecundity in herbivorous insects. Annu. Rev. Entomol. 47, 817-844. doi: 10.1146/annurev.ento.47.091201.145300

Bais, H. P., Weir, T. L., Perry, L. G., Gilroy, S., and Vivanco, J. M. (2006). The Role of root exudates in rhizosphere interactions with plants and other organisms. Annu. Rev. Plant Biol. 57, 233-266. doi: 10.1146/annurev.arplant.57.032905.105159

Barbosa, P., Hines, J., Kaplan, I., Martinson, H., Szczepaniec, A., and Szendrei, Z. (2009). Associational resistance and associational susceptibility: having right or wrong neighbors. Annu. Rev. Ecol. Evol. Syst. 40, 1-20. doi: 10.1146/annurev.ecolsys.110308.120242

Bever, J. D., Westover, K. M., and Antonovics, J. (1997). Incorporating soil community in plant population dynamics. J. Ecol. 85, 561-573. doi: $10.2307 / 2960528$ draft of the manuscript. All authors contributed to the final submitted version.

\section{ACKNOWLEDGMENTS}

We are grateful to smallholder farmers in Lake Victoria basin, Kenya for allowing us to collect soil from their farms. We thank Dickens Nyagol, Silas Ouko, Polycarp Bondo, and Aloice Ndiege for field assistance; Amos Gadi, Isaac Odera, Daniel Simiyu, and Olivia McCandless for assistance in insect rearing and screen house operations; Dr. Erika Mudrak of the Cornell Statistical Consulting Unit for the data analysis advice. Funding for this study was provided by an Academic Venture Fund and a Postdoctoral Fellowship Award from the Atkinson Center for Sustainable Future at Cornell University. ICIPE acknowledges financial support from its core http://www.icipe.org/donors-andpartners/core-donors and project donors http://www.icipe.org/ donors-and-partners/project-donors.

\section{SUPPLEMENTARY MATERIAL}

The Supplementary Material for this article can be found online at: https://www.frontiersin.org/articles/10.3389/fevo. 2019.00217/full\#supplementary-material

Bommarco, R., Kleijn, D., and Potts, S. G. (2013). Ecological intensification: harnessing ecosystem services for food security. Trends Ecol. Evol. 28, 230-238. doi: 10.1016/j.tree.2012.10.012

Cambier, V., Hance, T., and Hoffmann, E. (2000). Variation of DIMBOA and related compounds content in relation to the age and plant organ in maize. Phytochemistry 53, 223-229. doi: 10.1016/S0031-9422(99)00498-7

Chau, L. M., and Heong, K. L. (2005). Effects of organic fertilizers on insect pest and diseases of rice. Omonrice 33, 26-33. Available online at: https://www.clrri. org/ver2/uploads/noidung/13-4.pdf

Cook, S. M., Khan, Z. R., and Pickett, J. A. (2007). The use of push-pull strategies in integrated pest management. Annu. Rev. Entomol. 52, 375-400. doi: 10.1146/annurev.ento.52.110405.091407

De Deyn, G. B., Cornelissen, J. H. C., and Bardgett, R. D. (2008). Plant functional traits and soil carbon sequestration in contrasting biomes. Ecol. Lett. 11, 516-531. doi: 10.1111/j.1461-0248.2008.01164.x

Detheridge, A. P., Brand, G., Fychan, R., Crotty, F. V., Sanderson, R., Griffith, G. W., et al. (2016). The legacy effect of cover crops on soil fungal populations in a cereal rotation. Agric. Ecosyst. Environ. 228, 49-61. doi: 10.1016/j.agee.2016.04.022

Dias, T., Dukes, A., and Antunes, P. M. (2014). Accounting for soil biotic effects on soil health and crop productivity in the design of crop rotations. J. Sci. Food Agric. 95, 447-454. doi: 10.1002/jsfa.6565

Drinkwater, L. E., Wagoner, P., and Sarrantonio, M. (1998). Legume-based cropping systems have reduced carbon and nitrogen losses. Nature 396, 262-265. doi: $10.1038 / 24376$

Eigenbrode, S. D., and Pimentel, D. (1988). Effects of manure and chemical fertilizers on insect pest populations on collards. Agric. Ecosyst. Environ. 20, 109-125. doi: 10.1016/0167-8809(88)90151-X

Ewel, J. J., Mazzarino, M., and Cory, B. (1991). Tropical soil fertility changes under monocultures and successional communities of different structure. Ecol. Appl. 1, 289-302. doi: 10.2307/1941758

Fahad, S., Hussain, S., Bano, A., Saud, S., Hassan, S., and Shan, D. (2015). Potential role of phytohormones and plant growth-promoting rhizobacteria in abiotic stresses: consequences for changing environment. Environ. Sci. Pollut. Res. 22, 4907-4921. doi: 10.1007/s11356-014-3754-2 
Frey, M., Schullehner, K., Dick, R., Fiesselmann, A., and Gierl, A. (2009). Benzoxazinoid biosynthesis, a model for evolution of secondary metabolic pathways in plants. Phytochemistry 70, 1645-1651. doi: 10.1016/j.phytochem.2009.05.012

Garibaldi, L. A., Carvalheiro, L. G., Vaissière, B. E., Gemmill-Herren, B., Hipólito, J., Freitas, B. M., et al. (2016). Mutually beneficial pollinator diversity and crop yield outcomes in small and large farms. Science 351, 388-391. doi: $10.1126 /$ science.aac7287

Halitschke, R., Hamilton, J. G., and Kessler, A. (2011). Herbivorespecific elicitation of photosynthesis by mirid bug salivary secretions in the wild tobacco Nicotiana attenuata. New Phytol. 191, 528-535. doi: 10.1111/j.1469-8137.2011.03701.x

Harrison, K. A., and Bardgett, R. D. (2010). Influence of plant species and soil conditions on plant-soil feedback in mixed grassland communities. J. Ecol. 98, 384-395. doi: 10.1111/j.1365-2745.2009.01614.x

Harrison, X. A. (2014). Using observation-level random effects to model overdispersion in count data in ecology and evolution. PeerJ 2:e616. doi: $10.7717 /$ peerj. 616

Howard, M. M., Kalske, A., and Kessler, A. (2018). Eco-evolutionary processes affecting plant-herbivore interactions during early community succession. Oecologia 187, 547-559. doi: 10.1007/s00442-018-4088-4

Kessler, A., and Kalske, A. (2018). Plant secondary metabolite diversity and species interactions. Annu. Rev. Ecol. Evol. Syst. 49, 1-24. doi: 10.1146/annurev-ecolsys-110617-062406

Kessler,., A., and Baldwin, I. T. (2002). Plant responses to insect herbivory: the emerging molecular analysis. Annu. Rev. Plant Biol. 53, 299-328. doi: 10.1146/annurev.arplant.53.100301.135207

Kfir, R., Overholt, W. A., Khan, Z. R., and Polaszek, A. (2002). Biology and management of economically important lepidopteran cereal stem borers in Africa. Annu. Rev. Entomol. 47,701-731. doi: 10.1146/annurev.ento.47.091201.145254

Khan, Z., Midega, C. A. O., Hooper, A., and Pickett, J. (2016). Push-Pull: chemical ecology-based integrated pest management technology. J. Chem. Ecol. 42, 689-697. doi: 10.1007/s10886-016-0730-y

Khan, Z. R., Ampong-Nyarko, K., Chiliswa, P., Hassanali, A., Kimani, S., Lwande, W., et al. (1997). Intercropping increases parasitism of pests. Nature 388, 631-632. doi: 10.1038/41681

Khan, Z. R., Midega, C. A. O., Bruce, T. J. A., Hooper, A. M., and Pickett, J. A. (2010). Exploiting phytochemicals for developing a "push-pull" crop protection strategy for cereal farmers in Africa. J. Exp. Bot. 61, 4185-4196. doi: $10.1093 /$ jxb/erq229

Khan, Z. R., Midega, C. A. O., Pittchar, J., Bruce, T. J. A., and Pickett, J. A. (2012). "Push-Pull" Revisited: the process of successful deployment of a chemical ecology based pest management tool," in Biodiversity and Insect Pests: Key Issues for Sustainable Management, eds G. M. Gurr, S. D. Wratten, W. E. Snyder, and D. M. Y. Read (Chichester: Wiley-Blackwell), 259-275. doi: 10.1002/9781118231838.ch16

Kollner, T. G., Held, M., Lenk, C., Hiltpold, I., Turlings, T. C. J., Gershenzon, J., et al. (2008). A Maize (E)-caryophyllene synthase implicated in indirect defense responses against herbivores is not expressed in most American maize varieties. Plant Cell Online 20, 482-494. doi: 10.1105/tpc.107.051672

Kremen, C., and Miles, A. (2012). Ecosystem services in biologically diversified versus conventional farming systems: benefits, externalities, and trade-offs. Ecol. Soc. 17:40. doi: 10.5751/ES-05035-170440

Kumar, H. (1986). Enhancement of oviposition by Chilo partellus (Swinhoe) (Lepidoptera: Pyralidae) on maize plants by larval infestation. Appl. Entomol. Zool. 21, 539-545. doi: 10.1303/aez.21.539

Lacanne, C. E., and Lundgren, J. G. (2017). Regenerative agriculture: merging farming and natural resource conservation profitably. PeerJ 6:e4428. doi: $10.7717 /$ peerj. 4428

Ma, H.-K., Pineda, A., van der Wurff, A. W. G., Raaijmakers, C., and Bezemer, T. M. (2017). Plant-soil feedback effects on growth, defense and susceptibility to a soil-borne disease in a cut flower crop: species and functional group effects. Front. Plant Sci. 8:2127. doi: 10.3389/fpls.2017.02127

Magdoff, F. (1993). Building soils for better crops. Soil Sci. 156:371. doi: 10.1097/00010694-199311000-00014

Meyer, G. A. (2000). Interactive effects of soil fertility and herbivory on Brassica nigra. Oikos 88, 433-441. doi: 10.1034/j.1600-0706.2000.880221.x
Midega, C. A. O., Pittchar, J. O., Pickett, J. A., Hailu, G. W., and Khan, Z. R. (2018). A climate-adapted push-pull system effectively controls fall armyworm, Spodoptera frugiperda (J E Smith), in maize in East Africa. Crop Prot. 105, 10-15. doi: 10.1016/j.cropro.2017.11.003

Mutyambai, D. M., Bruce, T. J. A., Midega, C. A. O., Woodcock, C. M., Caulfield, J. C., van Den Berg, J., et al. (2015). Responses of parasitoids to volatiles induced by Chilo partellus oviposition on Teosinte, a wild ancestor of maize. J. Chem. Ecol. 41, 323-329. doi: 10.1007/s10886-015-0570-1

Mutyambai, D. M., Midega, C. A. O., Bruce, T. J. A., van den Berg, J., Pickett, J. A., and Khan, Z. R. (2014). Behaviour and biology of Chilo partellus on maize landraces. Entomol. Exp. Appl. 153, 170-181. doi: 10.1111/eea.12237

Niemeyer, H. (2009). Hydroxamic acids derived from 2-hydroxy-2 H-1, 4benzoxazin-3 (4 H)-one: key defense chemicals of cereals. J. Agric. Food Chem. 3, 1677-1696. doi: 10.1021/jf8034034

Niemeyer, H. M. (1988). Hydroxamic acids (4-hydroxy-1,4-benzoxazin-3ones), defence chemicals in the gramineae. Phytochemistry 27, 3349-3358. doi: 10.1016/0031-9422(88)80731-3

Ntiri, E. S., Calatayud, P., Musyoka, B., Van den Berg, J., and Le Ru, B. P. (2018). Influence of feeding-damaged plants on the oviposition responses within a community of female moths. Phytoparasitica 46, 607-615. doi: 10.1007/s12600-018-0695-1

Ochieng, R. S., Onyango, F. O., and Bungu, M. D. O. (1985). Improvement of techniques for mass-culture of Chilo partellus (Swinhoe). Insect Sci. Appl. 6, 425-428. doi: 10.1017/S1742758400004744

Oluwafemi, S., Bruce, T. J. A., Pickett, J. A., Ton, J., and Birkett, M. A. (2011). Behavioral responses of the leafhopper, Cicadulina storeyi China, a major vector of maize streak virus, to volatile cues from intact and leafhopper-damaged maize. J. Chem. Ecol. 37, 40-48. doi: 10.1007/s10886-01 0-9891-2

Päts, P. (1991). Activity of Chilo partellus (Lepidoptera: Pyralidae): eclosion, mating and oviposition time. Bull. Entomol. Res. 81,93-96. doi: $10.1017 /$ S0007485300053281

Petersen, B., and Snapp, S. (2015). What is sustainable intensification? Views from experts. Land Use Policy 46, 1-10. doi: 10.1016/j.landusepol.2015.02.002

Picasso, V. D., Brummer, E. C., Liebman, M., Dixon, P. M., and Wilsey, B. J. (2008). Crop species diversity affects productivity and weed suppression in perennial polycultures under two management strategies. Crop Sci. 48, 331-342. doi: 10.2135/cropsci2007.04.0225

Pickett, J. A., Woodcock, C. M., Midega, C. A. O., and Khan, Z. R. (2014). Push-pull farming systems. Curr. Opin. Biotechnol. 26, 125-132. doi: $10.1016 /$ j.copbio.2013.12.006

Pineda, A., Zheng, S. J., van Loon, J. J. A., Pieterse, C. M. J., and Dicke, M. (2010). Helping plants to deal with insects: the role of beneficial soil-borne microbes. Trends Plant Sci. 15, 507-514. doi: 10.1016/j.tplants.2010.05.007

Poveda, K., Gómez, M. I., Halitschke, R., and Kessler, A. (2012). Overcompensating plants: their expression of resistance traits and effects on herbivore preference and performance. Entomol. Exp. Appl. 143:245-253. doi: 10.1111/j.1570-7458.2012.01256.x

Poveda, K., Kessler, A., and Gómez, M. I. (2010). The enemy as ally: herbivore-induced increase in crop yield. Ecol. Appl. 20, 1787-1793. doi: 10.1890/09-1726.1

Probert, M. E., Fergus, I. E., Bridge, B. J., McGarry, D., Thompson, C. H., and Russell, J. S. (1987). The Properties and Management of Vertisols. Wallingford: CAB International.

R Development Core Team. (2017). R: A Language and Environment for Statistical Computing. Vienna: R Foundation for statistical computing. Available online at: http://www.R-project.org/

Ramesh, P., Singh, M., and Subba Rao, A. (2005). Organic farming: its relevance to the Indian context. Curr. Sci. 88, 561-568. Available online at: http://www.jstor. org/stable/24110255

Reiss, E. R., and Drinkwater, L. E. (2018). Cultivar mixtures: a meta-analysis of the effect of intraspecific diversity on crop yield. Ecol. Appl. 28, 62-77. doi: 10.1002/eap.1629

Römheld, V., and Kirkby, E. A. (2010). Research on potassium in agriculture: needs and prospects. Plant Soil 335, 155-180. doi: 10.1007/s11104-01 0-0520-1

Schneider, C. A., Rasband, W. S., and Eliceiri, K. W. (2012). NIH Image to ImageJ: 25 years of image analysis. Nat. Methods 9, 671-675. doi: 10.1038/nmeth.2089 
Sétamou, M., Schulthess, F., Bosque-Pérez, N. A., and Odjo-Thomas, A. (1993). Effect of plant nitrogen and silica on the bionomics of Sesamia calamistis (Lepidoptera: Noctuidae). Bull. Entomol. Res. 83, 405-411. doi: 10.1017/S000748530002931X

Sherwood, S., and Uphoff, N. (2000). Soil health: research, practice and policy for a more regenerative agriculture. Appl. Soil Ecol. 15, 85-97. doi: 10.1016/S0929-1393(00)00074-3

Stamp, N. (2003). Out of the quagmire of plant defense hypotheses. Q. Rev. Biol. 78, 23-55. doi: 10.1086/367580

Tamiru, A., Bruce, T. J. A., Midega, C. A. O., Woodcock, C. M., Birkett, M. A., Pickett, J. A., et al. (2012). Oviposition induced volatile emissions from african smallholder farmers' maize varieties. J. Chem. Ecol. 38, 231-234. doi: 10.1007/s10886-012-0082-1

Tamiru, A., Bruce, T. J. A., Woodcock, C. M., Caulfield, J. C., Midega, C. A. O., Ogol, C. K. P. O., et al. (2011). Maize landraces recruit egg and larval parasitoids in response to egg deposition by a herbivore. Ecol. Lett. 14, 1075-1083. doi: 10.1111/j.1461-0248.2011.01674.x

Van der Putten, W. H., Bardgett, R. D., Bever, J. D., Bezemer, T. M., Casper, B. B., Fukami, T., et al. (2013). Plant-soil feedbacks: the past, the present and future challenges. J. Ecol. 101, 265-276. doi: 10.1111/1365-2745.12054

von Mérey, G. E., Veyrat, N., D’Alessandro, M., and Turlings, T. C. J. (2013). Herbivore-induced maize leaf volatiles affect attraction and feeding behavior of Spodoptera littoralis caterpillars. Front. Plant Sci. 4:209. doi: 10.3389/fpls.2013. 00209
Wardle, D. A., Bardgett, R. D., Klironomos, J. N., Setälä, H., Van Der Putten, W. H., and Wall, D. H. (2004). Ecological linkages between aboveground and belowground biota. Science 304, 1629-1633. doi: 10.1126/science.10 94875

Wardle, D. A., Yeates, G. W., Williamson, W., and Bonner, K. I. (2003). The response of a three trophic level soil food web to the identity and diversity of plant species and functional groups. Oikos 102, 45-56. doi: 10.1034/j.1600-0706.2003. 12481.x

Wehrens, R. (2018). Alsace: ALS for the Automatic Chemical Exploration of Mixtures. R Package Version 1.18.0. Available online at: https:/github.com/ rwehrens/alsace (accessed January 22, 2019).

Conflict of Interest Statement: The authors declare that the research was conducted in the absence of any commercial or financial relationships that could be construed as a potential conflict of interest.

Copyright (c) 2019 Mutyambai, Bass, Luttermoser, Poveda, Midega, Khan and Kessler. This is an open-access article distributed under the terms of the Creative Commons Attribution License (CC BY). The use, distribution or reproduction in other forums is permitted, provided the original author(s) and the copyright owner(s) are credited and that the original publication in this journal is cited, in accordance with accepted academic practice. No use, distribution or reproduction is permitted which does not comply with these terms. 